\title{
Young's modulus of titanium alloy VT6S and its structural sensitivity
}

\author{
R.Ya. Lutfullin ${ }^{1, \uparrow}$, E.A. Trofimov ${ }^{1}$, R.M. Kashaev ${ }^{1}$, V.D. Sitdikov², T.R. Lutfullin ${ }^{1,2}$ \\ †lutram@anrb.ru
}

${ }^{1}$ Institute for Metals Superplasticity Problems RAS, 39 Khalturin St., Ufa, 450001, Russia

${ }^{2}$ Ufa State Aviation Technical University, 12 K. Marx St., 450000, Russia

\begin{abstract}
According to literature data, values of Young's modulus, $E$, measured in a two-phase titanium alloy VT6 (Ti-6Al-4V) can vary from 90 to $145 \mathrm{GPa}$. Elasticity modulus is an important material parameter, which enters the basic equations describing the structural strength of materials. Due to such a wide scatter of $E$ values, there is a problem of a correct choice of this parameter for the strength analyses of responsible aircraft structures. This also makes doubtful the accuracy of computational models assuming a constancy and structural insensivity of Young's modulus of an alloy used. An absence of systematic data in this field requires carrying out experiments, which would allow one to estimate the stability of elastic and strength properties of VT6-type two-phase titanium alloys subjected to long term processing at superplastic deformation temperatures, i.e. about $900^{\circ} \mathrm{C}$. Experiments carried out in the present paper have shown that long-term vacuum annealing of sheet titanium alloy VT6S with an initial average grain size of $1 \mu \mathrm{m}$ at $900^{\circ} \mathrm{C}$ for 50 hours leads to a considerable, about $14 \%$, reduction in Young's modulus. The average grain size increases up to $6 \mu \mathrm{m}$ during 50 hours annealing. Along with the reduction of elastic properties, a considerable, about $14 \%$ too, decrease in the room temperature tensile strength has been found. Vacuum annealing at $900^{\circ} \mathrm{C}$ preserves the existing anisotropy of mechanical properties, which is inherited due to a weak change of the original crystallographic texture. The revealed change of mechanical properties in sheet of titanium alloy VT6S after vacuum annealing correlates with structural changes including changes in phase composition and crystallographic texture.
\end{abstract}

Keywords: titanium alloy, Young's modulus.

\section{Нормальный модуль упругости титанового сплава ВТ6С и его чувствительность к изменению структуры}

\author{
Лутфуллин Р.Я., ${ }^{1, \dagger}$ Трофимов Е.А. ${ }^{1}$, Кашаев Р.М. ${ }^{1}$, Ситдиков В.Д. ${ }^{2}$, Лутфуллин T.P. ${ }^{1,2}$ \\ ${ }^{1}$ Институт проблем сверхпластичности металлов РАН, ул. Халтурина 39, 450001, Уфа, Россия \\ 2Уфимский государственный авиационный технический университет, ул. К. Маркса 12, 450000, Уфа, Россия
}

\begin{abstract}
Значения нормального модуля (Юнга) упругости (E), измеренные в двухфазных титановых сплавах типа ВТ6 (аналоги зарубежного сплава Ti-6Al-4V), согласно сведениям из научно-технической литературы могут варьироваться от 90 до 145 ГПа. Модуль упругости входит в основные уравнения конструкционной прочности материала. Поэтому наблюдаемый широкий разброс создает проблему корректного выбора значения $E$ при проведении прочностных расчетов авиационных конструкций ответственного назначения, а также ставит под сомнение точность расчетных моделей, подразумевающих постоянство и структурную нечувствительность нормального модуля упругости используемого сплава. Отсутствие системных научных данных определило актуальность проведения экспериментов, позволяющих оценить стабильность упругих и прочностных свойств в двухфазных титановых сплавах типа ВТ6 после длительного нахождения их при температуре проявления сверхпластической деформации, составляющей $900^{\circ} \mathrm{C}$. Проведенные эксперименты показали, что длительный вакуумный отжиг в течение 50 часов при $900^{\circ} \mathrm{C}$ листовых заготовок из титанового сплава ВТ6С с исходным средним размером зерен 1 мкм приводит к заметному снижению ( $14 \%$ в продольном направлении) нормального модуля упругости. Средний размер зерен в процессе 50-и часового отжига увеличился до 6 мкм. Наряду с уменьшением упругих свойств, выявлено также заметное понижение (на $14 \%$ ) предела прочности при комнатной температуре. Вакуумный отжиг при $900^{\circ} \mathrm{C}$ сохраняет имеющуюся в исходном листе ярко выраженную анизотропию механических свойств, наследуемую из-за слабого изменения исходной кристаллографической текстуры. Выявленный характер изменения механических свойств в листах титанового сплава ВТ6С после вакуумного отжига коррелирует со структурными изменениями, изменением фазового состава и кристаллографической текстурой.
\end{abstract}

Ключевые слова: титановый сплав, нормальный модуль упругости. 


\section{1. Введение}

Относительно недавно, принято было считать [1], что модуль нормальной упругости для чистых металлов является структурно нечувствительной величиной. Между тем, многочисленные экспериментальные исследования свидетельствуют о заметном снижении значений модуля упругости чистых металлов при переходе от крупнозернистого (КЗ) к наноструктурному состоянию [2-4]. Этот факт ставит под сомнение возможность широкого использования наноструктурных металлических материалов в качестве конструкционных для ответственных силовых изделий авиакосмического назначения. Конструкторы и другие специалисты-машиностроители не имеют также ясного ответа на вопрос о стабильности модуля упругости в титановых сплавах после различных видов термической и термомеханической обработки. В этой связи актуальным является оценка стабильности упругих свойств двухфазных титановых сплавов типа ВТ6. Титановые сплавы типа ВT6 (зарубежный аналог - сплав Ti-6Al-4V) являются своеобразной «рабочей лошадкой» для авиационного машиностроения, из которых, в частности, изготавливается полая лопатка вентилятора современного гражданского авиационного двигателя [5]. Надежность авиационной лопатки в эксплуатации, ее прочностные и частотные характеристики не в последнюю очередь определяются стабильным значением модуля упругости материала авиационной конструкции. Модули упругости входят во все основные уравнения конструкционной прочности материала. В этой связи уместно отметить, что значения нормального модуля упругости $(E)$, измеренные для двухфазных титановых сплавов типа ВТ6, согласно анализа данных из научной литературы варьируются от 90 до 145 ГПа [2].

Цель настоящей работы - оценить стабильность упругих и прочностных свойств в двухфазных титановых сплавах типа ВТ6 после их длительной выдержки при температуре проявления сверхпластичности, составляющей $900^{\circ} \mathrm{C}[6]$.

\section{2. Материал и методика эксперимента}

Объектом исследования служил промышленный двухфазный титановый сплав ВТ6 в микрокристаллическом (МК), ультрамелкозернистом (УМЗ) и крупнозернистом состояниях. Химический состав исследуемого сплава ВТ6 соответствовал ГОСТ 19807 -91. Исследовали также промышленные листы титанового сплава ВТ6С толщиной 1 мм с микрозернистой структурой (средний размер зерен 1 мкм) производства ВерхнеСалдинского металлургического производственного объединения (ВСМПО). Титановый сплав ВТ6С представляет согласно ГОСТ 19807-91 вариацию сплава BT6, легированного по нижнему пределу. Температура полного полиморфного превращения $(\alpha+\beta) \rightarrow \beta$ для исследуемых сплавов ВТ6 и ВТ6С составила 980 и $970^{\circ} \mathrm{C}$, соответственно.

Исходное УМЗ состояние в титановом сплаве ВТ6 было получено всесторонней изотермической ковкой с понижением температуры на последней стадии ковки до $600^{\circ} \mathrm{C}$ закаленных из $\beta$-области заготовок с последующей изотермической прокаткой при температуре $600^{\circ} \mathrm{C}$ [5,7]. Такая обработка обеспечивала УМЗ структуру со средним размером зерен 0,18 мкм. Полученные листовые заготовки с УМЗ структурой подвергали вакуумному отжигу. Мелкозернистую структуру получали вакуумным отжигом при температуре $900^{\circ} \mathrm{C}$ в течение 1 часа, что позволяло получить средний размер зерен около 5 мкм. Вакуумный отжиг УМЗ образцов сплава ВТ6 при $995^{\circ} \mathrm{C}$ в течение 1 часа обеспечил получение $\beta$-превращенных зерен величиной 103 мкм. Образцы из промышленного листа сплава ВТ6С отжигали в вакууме при температуре $900^{\circ} \mathrm{C}$ в течение 0,$25 ; 25$ и 50 часов.

Механические испытания на растяжение плоских образцов при комнатной температуре проводили на испытательной машине фирмы «Инстрон» модели 5982. Площадь рабочей части образца составляла $30 \times 5$ мм² $^{2}$. Скорость растяжения была 1 мм/мин. Для определения нормального модуля упругости использовали экстензометр с базой 12,5 мм.

Микротвердость исследуемых образцов определяли на микротвердомере «Axiovert - 100A» с микротвердомерной приставкой «МНТ -10» и системой анализа изображения «KS - 300». При этом прикладываемая нагрузка на алмазный индентор составляла 150 г.

Количественное содержание $\alpha$ - и $\beta$-фаз в исследуемом сплаве определяли при комнатной температуре на металлографических микрошлифах точечным методом А. А. Глаголева [8] с ошибкой, не превышающей $2 \%$. Использовали сканирующий электронный микроскоп «TESCAN MIRA3 LMU».

Для рентгеноструктурного анализа (РСA) использовали данные съемки полученные на дифрактометре Rigaku Ultima IV с фокусировкой гониометра по методу Брэгга-Брентано. Для выявления пиков использовалось фильтрованное медное излучение. Съёмка образцов проводилась при напряжении 40 кВ и токе 40 мА. Для расчетов использовалась длина волны $\lambda_{\text {ка1 }}=1.54060 \AA$. Общий вид рентгенограмм снимался с шагом сканирования $0.02^{\circ}$ и временем экспозиции в каждой точке, равным 3 секундам в интервале углов $2 \Theta$ от $5^{\circ}$ до $120^{\circ}$. Качественный и количественный фазовый анализ, оценка параметра решетки, размеров областей когерентного рассеяния, среднеквадратических микроискажений проводились с использованием программного пакета PDXL (www.rigaku.com).

\section{3. Результаты и их обсуждение}

Ультрамелкозернистая (УМЗ) структура обеспечивает высокий комплекс механических и технологических свойств, что определяет востребованность, например, титановых полуфабрикатов с такой структурой для изготовления изделий повышенного качества [5-7]. Фундаментальным физическим и механическим свойством металлов и сплавов является, в частности, нормальный модуль упругости. Эта характеристика широко используется при различных прочностных расчетах конструкций. Между тем, в процессе термической и термо-меха- 
нических обработок УМЗ структура эволюционирует $[5-7,9-11]$. В этой связи рассмотрим результаты механических испытаний на растяжение при комнатной температуре образцов титанового сплава ВТ6 с исходной УМЗ структурой после вакуумного отжига при температурах 900 и $995^{\circ} \mathrm{C}$. Эти данные представлены в таблице 1 [12]. Анализ таблицы 1 позволяет выявить четкую тенденцию к снижению нормального модуля $E$, которая наблюдается на фоне увеличения среднего размера зерен в титановом сплаве ВТ6, но в действительности связана с изменением фазового состава в сторону увеличения количества $\beta$-фазы [12]. В научно-технической литературе на сегодняшний момент отсутствуют экспериментальные данные по оценке нормального модуля упругости в двухфазных титановых сплавах типа BT6 после длительного отжига при $900^{\circ} \mathrm{C}$. Между тем, эти данные также важны, так как в процессе технологического изготовления ответственных изделий авиационного двигателя, таких как, например, полая лопатка [5], титановый сплав подвергается длительному темпе- ратурному воздействию, что, вполне вероятно, может заметно отразиться на конструкционной прочности полого изделия. Результаты механических испытаний образцов титанового сплава ВТ6С после длительного вакуумного отжига представлены в таблице 2.

Следует отметить, что при длительном отжиге при температуре $900^{\circ} \mathrm{C}$ средний размер зерен в сплаве ВТ6С увеличился с 1 до 6 мкм (рис. 1), при этом как показали результаты механических испытаний (табл. 2), нормальный модуль упругости в продольном направлении заметно снизился со 120,2 до 103,1 ГПа. Oсобенностью исследуемых листов сплава ВТ6С, как следует из анализа данных таблицы 2, является наличие существенной анизотропии упругих и прочностных свойств. Так, например, разница нормального модуля упругости в исходном листе сплава ВТ6С вдоль и поперек прокатки составляет $18 \%$, при этом примечательно, что длительный вакуумный отжиг при $900^{\circ} \mathrm{C}$ не приводит к снижению анизотропии упругих и прочностных характеристик.

Табл. 1. Результаты механических испытаний титанового сплава ВТ6 с различным размером зерна.

Table 1. The results of mechanical tests of titanium alloy VT6 with different grain size.

\begin{tabular}{|c|c|c|c|c|}
\hline $\begin{array}{c}\text { Размер зерен, мкм } \\
\text { Grain size, } \mu \mathrm{m}\end{array}$ & $\begin{array}{c}\text { E, ГПа } \\
\text { E, GPa }\end{array}$ & $\begin{array}{c}H_{V}, \mathrm{M \Pi а} \\
H_{V}, \mathrm{MPa}\end{array}$ & $\begin{array}{c}\sigma_{\mathrm{s}}, \mathrm{M \Pi а} \\
\sigma_{\text {uts }}, \mathrm{MPa}\end{array}$ & $\begin{array}{c}\delta, \mathrm{M \Pi а} \\
\delta, \mathrm{MPa}\end{array}$ \\
\hline $\begin{array}{c}0,18 \text { (исходная УМ3 структура) } \\
0,18 \text { (initial UFG structure) }\end{array}$ & 117,4 & 5320 & 1331 & 21 \\
\hline $\begin{array}{c}5 \text { (отжиг }-900^{\circ} \mathrm{C} \text { ) } \\
5 \text { (annealing }-900^{\circ} \mathrm{C} \text { ) }\end{array}$ & 106,4 & 4220 & 850 & 11 \\
\hline $\begin{array}{c}103 \text { (отжиг }-995^{\circ} \mathrm{C} \text { ) } \\
103\left(\text { annealing }-995^{\circ} \mathrm{C} \text { ) }\right.\end{array}$ & 95 & 4210 & 803 & \\
\hline
\end{tabular}

Табл. 2. Механические свойства сплава ВТ6С после растяжения при комнатной температуре вдоль и поперек прокатки листа. Table 2. Tensile mechanical properties of VT6S alloy at room temperature in the longitudinal and across direction of sheet.

\begin{tabular}{|c|c|c|c|c|c|c|}
\hline $\begin{array}{l}\text { Состояние сплава ВТ6С } \\
\text { Condition of VT6S alloy }\end{array}$ & $\begin{array}{c}E, \text { ГПа, вдоль } \\
E, \mathrm{GPa}, \\
\text { longitudenally }\end{array}$ & $\begin{array}{c}\text { E, ГПа, поперек } \\
\text { E, GPa, across }\end{array}$ & $\begin{array}{c}\sigma_{\mathrm{B}}, \mathrm{MПа,} \mathrm{вдоль} \\
\sigma_{\text {uts }}, \mathrm{MPa}, \\
\text { longitudenally }\end{array}$ & $\begin{array}{c}\sigma_{\mathrm{s}}, \mathrm{MПа}, \text { поперек } \\
\sigma_{\mathrm{uts}}, \mathrm{MPa}, \text { across }\end{array}$ & $\begin{array}{c}\delta, \%, \text { вдоль } \\
\delta, \%, \\
\text { longitudenally }\end{array}$ & $\begin{array}{c}\delta, \%, \text { поперек } \\
\delta, \% \text {, across }\end{array}$ \\
\hline $\begin{array}{l}\text { Исходный лист } \\
\text { Initial sheet }\end{array}$ & 120,2 & 142,4 & 851,5 & 987,2 & 8,9 & 9,0 \\
\hline $\begin{array}{c}\text { Вакуумный отжиг - } \\
900^{\circ} \mathrm{C}, 0,25 \text { ч. } \\
\text { Vacuum annealing - } \\
900^{\circ} \mathrm{C}, 0,25 \mathrm{~h} .\end{array}$ & 108,9 & - & 756,0 & 820,6 & 12,9 & 8,0 \\
\hline $\begin{array}{c}\text { Вакуумный отжиг - } \\
900^{\circ} \mathrm{C}, 25 \text { ч. } \\
\text { Vacuum annealing - } \\
900^{\circ} \mathrm{C}, 25 \mathrm{~h} .\end{array}$ & 104,9 & - & 752,0 & 846,5 & 11,9 & 8,0 \\
\hline $\begin{array}{l}\text { Вакуумный отжиг - } \\
900^{\circ} \mathrm{C}, 50 \text { ч. } \\
\text { Vacuum annealing - } \\
900^{\circ} \mathrm{C}, 50 \mathrm{~h} .\end{array}$ & 103,1 & 136,6 & 730,5 & 838,8 & 11,9 & 8,3 \\
\hline
\end{tabular}


В качестве отличий двухфазных титановых сплавов от чистых металлов, что очевидно, можно отметить возможность количественного изменения фазового состава при наличие преобладающей $\alpha$-фазы с анизотропной гексагональной плотноупакованной (ГПУ) решеткой. Эти факторы, по всей видимости, могут определять наблюдаемые отклонения в значениях нормального модуля упругости титанового сплава. В этой связи обратимся к полученным результатам.

Как показали эксперименты авторов [13], вакуумный отжиг сплава ВТ6C при $900^{\circ} \mathrm{C}$ приводит к увеличению количества $\beta$-фазы с объемно-центрированной кубической (ОЦК) решеткой при комнатной температуре от $10 \%$ для исходного состояния промышленного листа до $18 \%$ после 50-и часов отжига. При этом известно [12], что нормальные модули упругости $\alpha$ - и $\beta$-фаз в сплавах типа ВТ6 заметно различаются. Согласно работе [12], модуль упругости $\alpha$-фазы составил $-92,78$ ГПа, а $\beta$-фазы - 75,81 ГПа в крупнозернистом сплаве ВТ6 после вакуумного отжига при температуре $995^{\circ} \mathrm{C}$. Аналогичные результаты, свидетельствующие о повышенном модуле упругости гексагональной $\alpha$-фазы в сравнении с кубической $\beta$-фазой также получены авторами [14] для сплава Ti-6Al-4V, являющегося зарубежным аналогом сплава BT6. После изостатического прессования титанового сплава Ti-6Al-4V при температуре $900^{\circ} \mathrm{C}$ в течение 2 часов, модуль упругости $\alpha$-фазы при комнатной температуре составил 132,2 ГПа, а $\beta$-фазы - 81,1 ГПа. Определение модуля упругости авторы [14] осуществляли наноиндентированием по методу Оливера-Фарра.

Ранее нами было обнаружено [9], что в УМЗ состоянии сплава ВТ6 объемное количество ОЦК (объемноцентрированной кубической) $\beta$-фазы было уменьшенным и составляло всего $4 \%$, при этом сплав проявил повышенные упругие свойства. Эффект уменьшения количества $\alpha$-фазы в УМЗ титановом сплаве ВТ6, полученном интенсивной пластической деформацией, в частности, методом равноканального углового прессования (РКУП), впервые был выявлен авторами работы [15].

Таким образом, наблюдаемое снижение модуля упругости $E$ на фоне увеличения среднего размера зерна исследуемого сплава ВТ6С после отжига, то есть при переходе в более равновесное структурное состояние можно объяснить, в первую очередь, именно изменением фазового состава, проявляющегося в увеличение объемной доли относительно «мягкой» $\beta$-фазы. Известно [16], что титановые сплавы с преимущественным содержанием $\beta$-фазы перспективны в настоящее время для использования в травматологии как имплантаты именно из-за пониженного модуля упругости. Наиболее сложный вопрос, связанный с варьированием модуля упругости сплава ВТ6С связан с влиянием кристаллографической текстуры гексагональной $\alpha$-фазы, которая количественно является преобладающей. В работе [17] показано, что для листов титанового сплава ВТ6 с увеличением толщины листа происходят изменения в сторону снижения базисной текстуры $\alpha$-фазы в плоскости листа и увеличение интенсивности полюсов базиса в поперечном направлении, что сопровождается увеличением в этом направлении модуля Юнга.
В этой связи обратимся к результатам текстурных исследований титанового сплава ВТ6С, приведенных на рисунке 2, где представлены прямые полюсные фигуры для плоскостей призмы (100), базиса (002) и пирамиды (101) $\alpha$-фазы. В исходном образце преимущественно преобладает острая базисная (002) текстура, с интенсивностью 3,0 в условных единицах. Вакуумный отжиг при $900^{\circ} \mathrm{C}$ в течении 15 минут приводит лишь к слабому размытию текстуры. Незначительные текстурные изменения, вероятно и являются причиной сохраняющейся исходной анизотропии механических свойств в листовых заготовках сплава ВТ6С после вакуумного отжига при температуре $900^{\circ} \mathrm{C}$.

\section{4. Заключение}

1. Выявлено $14 \%$ снижение нормального модуля упругости в продольном направлении после вакуумного отжига при $900^{\circ} \mathrm{C}$ листов из промышленного титанового сплава ВТ6С, что вероятно в первую очередь связано с увеличением объемного количества ОЦК $\beta$-фазы.

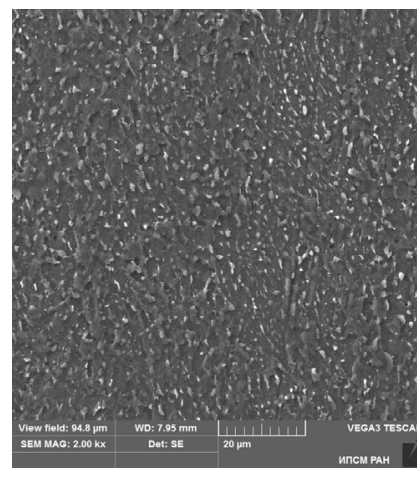

a

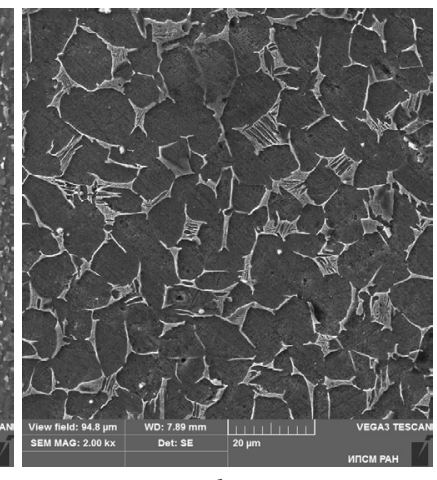

b
Рис. 1.Микроструктура титанового сплава ВТ6С - исходная (a); после вакуумного отжига при температуре $900^{\circ} \mathrm{C}$ в течение 50 часов (b).

Fig. 1. The microstructure of VT6S titanium alloy - initial (a); after vacuum annealing at temperature of $900^{\circ} \mathrm{C}$ for 50 hours (b).

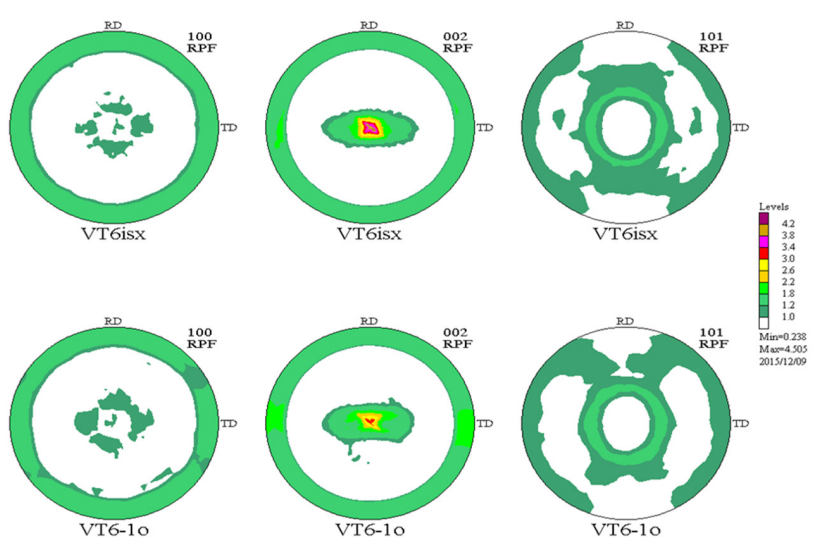

Pис. 2. (Color online) Полюсные фигуры для плоскостей призмы (100), базиса (002) и пирамиды (101) для листов титанового сплава ВТ6С в исходном состоянии (верхний ряд) и после вакуумного отжига при $900^{\circ} \mathrm{C}$ в течение 0,25 ч (нижний ряд).

Fig. 2. (Color online) Pole figures for the prism planes (100), the basis of (002) and pyramid (101) for sheets of titanium alloy VT6S in the initial state (top row) and after vacuum annealing at $900^{\circ} \mathrm{C}$ for 0.25 hours (lower row). 
2. Разница значений нормального модуля упругости вдоль и поперек прокатки исходных листов сплава ВТ6С составляет $18 \%$. Вакуумный отжиг при $900^{\circ} \mathrm{C}$ не приводит к снижению анизотропии нормального модуля упругости.

\section{Литература/References}

1. V. S. Zolotorevski. Mechanical properties of metals: Tutorial for universities. M., Metallurgy, 1983. 352 p. (in Russian) [В.С. Золоторевский. Механические свойства металлов: Учебник для вузов. М., Металлургия, 1983. 352 c.]

2. G. E. Fougere, L. Riester, M. Ferber, et al. Mat. Sci. Eng. A204, 1 -6 (1995), Doi: 10.1016/0921-5093 (95) $09927-1$

3. M. I. Alymov. Technology metals. 3, 8 (2000) (in Russian) [M.И. Алымов. Технология металлов. 3, 8 (2000)]

4. N. I. Noskova, R. R. Mulyukov. Submicrocrystalline and nanocrystalline metals and alloys. Ekaterinburg, UB RAS, 2003. 279 p. (in Russian) [Н. И. Носкова, Р. Р. Мулюков. Субмикрокристаллические и нанокристаллические металлы и сплавы. Екатеринбург, УрО РАН, 2003. 279 c.]

5. O.R. Valiakhmetov, R.M. Galeyev, R.M. Imayev, et al. Nanotechnologies in Russia. 5 (1-2) 102 (2010). Doi: 10.1134/S1995078010010118

6. O. A. Kaibyshev. Superplasticity of commercial alloys. M., Metallurgy, 1984. 264 p. (in Russian) [O.А. Кайбышев. Сверхпластичность промышленных сплавов. М., Металлургия, 1984. 264 с.]

7. G. A. Salischev, R.M. Galeyev, O.R. Valiakhmetov, et al. Journal of Materials Processing Technology. 116 (2-3) 265 (2001). Doi: 10.1016/S0924-0136 (01) 01037-8

8. S.A. Saltykov. Stereometric metallography. M.,
Metallurgy, 1976. 272 p. (in Russian) [C.А. Салтыков. Стереометрическая металлография. М., Металлургия, 1976. 272 c.]

9. E.A. Trofimov, R.U. Shayakhmetov, R. Ya. Lutfullin. Advanced materials. Special issue (15) 124 (2013). (in Russian) [E.A. Трофимов, Р.У. Шаяхметов, Р.Я. Лутфуллин. Перспективные материалы. Специальный выпуск (15). 124 (2013)]

10. R. Ya. Lutfullin, O. A. Kaibyshev, O. R. Valiakhmetov, et al. Journal of Advanced materials. 10 (4) 326 (2003).

11. R. Ya. Lutfullin, M.Kh. Mukhametrakhimov. Metal science and heat treatment. 211 (2006). Doi: 10.1007/s11041-006-0043-9

12. E. A. Trofimov, R. Ya. Lutfullin, R. M. Kashaev. Letters on materials. 5 (1) 67 (2015). Doi: 10.22226/2410-3535-201 5-1-67-69

13. E. A. Trofimov, T. R. Lutfullin, V. D. Sitdikov, R. M. Kashaev. Materials of the Russian Science Conference «Mavlutova reading», vol. 7. Ufa. (2016) p. 126-128. (in Russian) [Е.А. Трофимов, Т.Р. Лутфуллин, В.Д. Ситдиков, Р.М. Кашаев. Труды Российской научно-технической конференции «Мавлютовские чтения», том 7. Уфа. 2016. C. $126-128$.]

14. I. Sen, U. Ramamurty. Scripta Materialia. 6237 (2010). Doi: 10.1016/j.scriptamat.2009.09.022

15. I.P. Semenova, L. R. Saitova, R. K. Islamgaliev, et al. The Physics of Metals and Metallography. 100 (1) 66 (2005).

16. ASTM F 2066 Standart Specification for Wrought Titanium-15Molybdenum Alloy for Surgical Implant Applications (UNS R58150) - Annual Book of ASTM Standarts, ASTM International, West Conshohocken, PA, 2013. 5 p.

17. S. Ya. Betsofen, V.G. Smirnov, A.A. Ashmarin, A. A. Shaforostov. Titanium. 216 (2010) (in Russian) [С.Я. Бецофен, В.Г. Смирнов, А.А. Ашмарин, А. А. Шафоростов. Титан. 216 (2010)]. 